\title{
¿ANTROPOLOGÍA DE LA CIUDADANÍA?... ÉTNICA. EN CONSTRUCCIÓN DESDE AMÉRICA LATINA
}

\author{
Xochitl Leyva Solano
}

Resumen: En este artículo tomo como bilo conductor el concepto de ciudadania haciéndolo cruzar desde los campos de interés propios del derecho y la filosofía hacia el de la antropología. Ello es posible hacerlo hoy gracias a que científicos sociales de varias latitudes han acuñado términos como "ciudadanía cultural", "ciudadanía multicultural", "ciudadania intercultural" y "ciudadanía étnica". Este último concepto ha sido acuñado atendiendo principalmente la bistoria y la naturaleza de las demandas, los reclamos y las luchas que han llevado a cabo, desde el último cuarto del siglo XX, las comunidades, lideres, organizaciones y movimientos indigenas de América Latina. ¿Quiénes lo acuñaron? ¿Cuándo, dónde y para qué? ¿Qué aportes y qué límites encontramos al usarlo? ¿Quiénes lo están utilizando y bajo qué contextos? Tomando como punto de partida dicho término ¿se podría hablar de la existencia de un modelo interpretativo alternativo, emergente y propiamente latinoamericano?

Palabras clave: ciudadanía, étnico, líderes, organizaciones y movimientos indigenas, Estado nación, antropología de la ciudadanía, América Latina.

Enviado a dictamen: 15 de febrero de 2007.

Aprobación: 22 de mayo de 2007.

Xochitl Leyva Solano, investigadora del CIESAS-SURESTE, doctora en Antropología por la Universidad de Manchester, Inglaterra. Temas de especialización: estudios del poder, la política y los movimientos sociales en sociedades multi y pluri étnicas del sur de México y Centroamérica.
Abstract: The main argument of this article develops around the concept of citizenship which I will examine taking as a starting point contributions made in the fields of law studies, philosophy and anthropology. There have been considerable advances in the social sciences with the proposition and discussion of new composite concepts such as "multicultural citizenship", "intercultural citizenship", and "ethnic citizenship". With "ethnic citizenship" in particular, scholars have been trying to respond to the history and nature of the demands, claims and struggles that indigenous organisations and communities, movements and their leaders have made in Latin America over the past three decades. ¿Who proposed this concept, and when, where and for what purposes was it developed? What are the advantages and limits of "ethnic citizenship"? Who is using this concept now and in what social and political contexts? This discussion leads me to ask whether it is possible to speak of an emerging, alternative Latin American model of interpretation?

Key words: citizenship, ethnic, indigenous leaders, organizations and movements, nation state, anthropology of citizenship, Latin America.

$\mathrm{E}$ n este artículo tomo como hilo conductor el concepto de ciudadanía haciéndolo cruzar desde los campos de interés propios del derecho y la filosofía hacia el de la antropología. Ello es posible hacerlo hoy gracias a que científicos sociales de varias latitudes han acuñado términos como "ciudadanía cultural" (Rosaldo, 1985, 1989, 1994, 1997), “ciudadanía multicultural” (Kymlicka,

\section{5}

Revista LiminaR. Estudios sociales y bumanísticos, año 5, vol. V, núm. 1, junio de 2007, Tuxtla Gutiérrez, Chiapas. ISSN: 1665-8027 
1996), "ciudadanía intercultural" (Cortina, 1998) y "ciudadanía étnica” (Guerrero, 1990; Montoya, 1992; De la Peña, 1995). Este último concepto ha sido acuñado atendiendo principalmente la historia y la naturaleza de las demandas, los reclamos y las luchas que han llevado a cabo, desde el último cuarto del siglo XX, comunidades, líderes, organizaciones y movimientos indígenas de América Latina. ¿Quiénes acuñaron el concepto de "ciudadanía étnica"? ¿Cuándo, dónde y para qué? ¿Qué aportes y qué límites encontramos al usarlo? ¿Quiénes lo están utilizando y bajo qué contextos? Tomando como punto de partida dicho término ¿se podría hablar de la existencia de un modelo interpretativo alternativo, emergente y propiamente latinoamericano?

En este texto esperamos responder a dichas interrogantes y con ello abogar y abonar críticamente a favor del desarrollo y la consolidación de lo que Assies, Calderón y Salman (2002) han dado en llamar la "antropología de la ciudadanía”, que en pocas palabras propone ver la ciudadanía más allá de los elementos legales, jurídicos y formales para reubicar su discusión tomando en cuenta "las realidades vividas, la cultura, las estructuras políticas y de la sociedad civil que promueven, limitan o 'distorsionan' la realización de una ciudadanía plena” (Assies, Calderón y Salman, 2002: 18). Esta invitación nos obliga a ir más allá de unas ciencias sociales prescriptivas, nos insta a reconocer el carácter polisémico del concepto de ciudadanía y a tomar en cuenta "las estrategias cotidianas de poder entre agentes sociales así como los imaginarios acerca de la ciudadanía y sus configuraciones" (Assies, Calderón y Salman, 2002: 39).

La idea de escribir este texto nació años atrás cuando preparaba el artículo intitulado "Indigenismo, indianismo y 'ciudadania étnica' de cara a las redes neozapatistas" (Leyva 2002, 2005). Fue entonces cuando me di cuenta de que las luchas zapatistas e indígenas articuladas al EZLN tenían una gramática moral que podía analíticamente ser entendida usando el concepto de "ciudadanía étnica" con la finalidad heurística de resaltar que estábamos frente a reclamos de los zapatistas y de los indígenas organizados, mediante los cuales se exigía el reconocimiento de derechos diferenciados que ponían en jaque la noción liberal de democracia, igualdad y ciudadanía sobre la cual se había erigido el Estado mexicano. Pero no solamente se trataba de eso sino que en el texto también demostraba cómo y por qué existía entre el indigenismo, el indianismo y el (neo)zapatismo una serie de rupturas y continuidades que enumeré retomando algunos discursos y prácticas de los neozapatistas y de miembros del Congreso Nacional Indígena (CNI).

Fue a través de ese trabajo que me di cuenta de la desarticulación que existía entre autores latinoamericanos que trataban el mismo tema. En México por ejemplo, con sus honrosas excepciones, los pioneros sudamericanos del concepto "ciudadanía étnica” son casi desconocidos. ${ }^{2}$ No se diga de los autores extranjeros (y nacionales) inmersos en el debate de ciudadanía y cultura, quienes en muchos casos se refieren casi exclusivamente a la bibliografía producida en Europa central, Canadá y Norteamérica. Esto no fuera motivo de reflexión crítica si es que no llevara consigo una invisibilización de los aportes y del trabajo que los pensadores latinoamericanos están haciendo en este campo. Espero poder convencerlos de ello con este artículo. El lector podría pensar que voy solamente a proceder a sintetizar un debate existente. Creo yo, me puedo equivocar, que lo que existe a la fecha no llega todavía a ser un "debate sobre la ciudadanía 
étnica" para que lo fuera lo primero que tendríamos que saber toda la comunidad, es que hay pioneros, que ellos surgen en distintos contextos y que al ponerlos a dialogar y al seguirlos críticamente, de alguna forma, estamos contribuyendo a crear "el debate de la ciudadanía étnica" y de la "antropología de la ciudadanía” como propuesta surgida no necesariamente de las academias hegemónicas aunque sin duda en diálogo con ellas.

¿Cómo, cuándo y dónde surge

el concepto de ciudadanía étnica?

La "ciudadanía étnica" como concepto analítico fue enunciado tal cual por vez primera en 1990 por el historiador y sociólogo ecuatoriano Andrés Guerrero, dos años más tarde aparecería en los escritos del antropólogo peruano Rodrigo Montoya (1992), y tres años después lo utilizará también el antropólogo mexicano Guillermo de la Peña (1995). Lo interesante es que ninguno de los tres en ese momento citaba los escritos de los otros, ${ }^{3}$ por lo que parece más bien tratarse de un desarrollo intelectual paralelo dado primero en los países centroandinos (de Ecuador y Perú) y más tarde en el contexto mesoamericano mexicano y, ya para 1997, también en el guatemalteco (Bastos, 1997).

Como veremos en este texto dicho desarrollo intelectual paralelo no es casual pues las demandas de "ciudadanía étnica" tienen una dimensión latinoamericana. Al respecto Santiago Bastos en 1997 afirmaba que:

En América Latina, el surgimiento de actores étnicos los encontramos en los diversos movimientos indígenas que se han venido articulando desde hace más de 20 años... frente a la corriente anterior, las demandas indias no reivindican [hoy] solamente su "ciudadanía cultural”, sino que implican el reconocimiento de un nuevo tipo de actor, el colectivo, y una nueva ciudadanía, la "étnica". Este término de "ciudadanía étnica” está siendo cada vez más utilizado... para referirse al alcance que van tomando las demandas de estos grupos. Por tratarse de la conceptualización de algo que está en marcha y, por tanto, en proceso de definición en circunstancias muy variadas, sus contenidos específicos no están aún muy claros. Lo que sí se puede afirmar es que en su base se encuentra el considerar a los "pueblos" como sujetos de derecho por el hecho de ser diferentes al conjunto nacional en que están inscritos. Esto enfrenta las bases mismas de la doctrina liberal, tanto porque cuestiona la dimensión individual de los derechos, como porque, en contra de la visión universalista, introduce la diferencia como fuente de los mismos. Se produce entonces una serie de tensiones entre los intereses y demandas indígenas y los intereses y necesidades de los Estados, cuyo punto más conflictivo-simbólica y pragmáticamente- es la demanda siempre negada de autonomía territorial (Bastos, 1997: 2).

Pero revisemos paso por paso la historia, el desarrollo y el contenido del concepto acuñado en las tres latitudes latinoamericanas.

\section{Movimiento indígena, "ciudadanía étnica" y gobernabilidad}

En 1990 Andrés Guerrero dio una ponencia en el Centro de Investigación de los Movimientos Sociales del Ecuador, en la que habló de la "desintegración de la identidad étnica" en ese país; mostraba históricamente cómo los indígenas ecuatorianos habían pasado de 
"indios tributarios", en la época colonial, "sujetos indios", ante el Estado republicano, a ser "ciudadanos étnicos", sobre todo a partir del levantamiento de 1990. Andrés Guerrero regresó a este planteamiento en el libro colectivo publicado en 1993, en el que él y otros ya no sólo reflexionaban sobre Ecuador sino acerca del entrelazamiento entre democracia, etnicidad y violencia política en todo el mundo andino (Adrianzén et al., 1993).

En su texto publicado en 1993, Andrés Guerrero continuaba desarrollando su planteamiento original, pero priorizaba un período particular de la historia ecuatoriana: el que va de "la manifestación de 1961" al "levantamiento indígena de 1990" " . Guerrero revisaba los procesos sociales y las modificaciones estructurales ocurridas entre esos dos hitos de la historia para poder comprender los cambios en el sentido y naturaleza de las movilizaciones indígenas y en sus engarces con el sistema político nacional. El autor ponía especial énfasis en el estudio de las modificaciones históricas estructurales de lo que llamó la "administración étnica" en relación con la "cuestión agraria" y los poderes locales que mediaron entre el Estado central y las poblaciones indígenas.

Guerrero nos mostraba cómo en aquel diciembre de 1961 en la ciudad de Quito "la manifestación" silenciosa de entre 10 y 15 mil huasipungueros estaba sostenida por "masas" de indígenas miembros de una organización política "compuesta por mediadores externos blancos" de la Federación Ecuatoriana de Indios (FEI) "controlada" por el Partido Comunista ecuatoriano; a diferencia del "levantamiento de 1990", sostenido por un movimiento de base de alcance nacional, con liderazgos surgidos de las "nacionalidades indígenas" provenientes de la
Sierra y la Amazonia, autónomos, sin conexión con los partidos políticos y los sindicatos. Este aspecto le resultaba a Guerrero fundamental para repensar la ciudadanía más allá de los vínculos entre los individuos y el Estado nación.

Al respecto, Guerrero afirmaba que la FEI si bien desempeñó un papel clave para exigir la reforma agraria a comienzos de los años sesenta, y para llevar los conflictos de los huasipungueros a la arena nacional, también tuvo un papel de mediador y de traducción en el sentido de "ventriloquia", que reforzaba más bien reivindicaciones de "derechos de clase", mientras que con el movimiento indígena de los años noventa creó un "agente social que eslabonó e impulsó demandas antes impensables e indecibles por falta de discurso". Fueron demandas que articulaban exigencias de autonomía, autogobierno y autodeterminación, en las que los pueblos exigían un reconocimiento colectivo (en calidad de "ciudadanos étnicos") en sus vínculos con el Estado.

Andrés Guerrero cierra su texto, fechado en agosto de 1990, con la siguiente pregunta: "¿en qué medida el estado nacional ecuatoriano, en su proyecto y realidad, puede incluir una reformulación... centrada en el reconocimiento de una ciudadanía étnica o plurinacional (sic, las cursivas son mías)" en cuanto "creación de un vínculo inédito de derechos y obligaciones entre el estado nación y los pueblos indígenas"? (Guerrero, 1993: 101). La pregunta nos obliga a recordar que el autor está reflexionando justo a principios de la década de los noventa cuando apenas el movimiento indígena ecuatoriano empezaba a mostrarse como un actor clave para las transformaciones democráticas del país y para impulsar "algunas medidas de ajuste económico que evitaron el proceso privatizador de los 
servicios básicos estatales y la plena vigencia del modelo económico neoliberal" (Tibán y García, en prensa). Vale recordar que al primer levantamiento indígena nacional de 1990 (que exigió el reconocimiento plurinacional y una reforma política profunda) le siguió, en 1992, la marcha organizada por la Confederación de Nacionalidades Indígenas de la Amazonia Ecuatoriana (CONFENIAE), filial de la CONAIE, ${ }^{5}$ que exigía sobre todo la legalización de los territorios de las nacionalidades indígenas. Ya para 1994, el segundo levantamiento indígena nacional paralizó por veinte días el país entero en clara oposición a la liberalización de tierras comunitarias. Cinco años más tarde, en 1999, se llevarían acabo dos movilizaciones más en las que el movimiento indígena y sus aliados lograrían congelar el precio de los combustibles por un año. Y finalmente, el cierre de la década de los noventa se dio en verdad en el año 2000 , cuando se dolarizó la economía, medida que llevó a los movimientos ecuatorianos (sobre todo al indígena) a la toma espectacular de carreteras y de la ciudad de Quito para exigir la desaparición de los tres poderes y la instauración de un nuevo gobierno (Tibán y García, en prensa).

Sólo tomando en cuenta esta historia de movilizaciones es que se entiende la importancia del planteamiento pionero de los "ciudadanos étnicos" como modelo de interpretación que surge justo en el momento en que se da un "viraje temático" y teórico en los estudios políticos ecuatorianos, mismos que estaban dejando atrás el análisis de la transición y las elecciones y empezaban a enfocarse más en los de la democracia, la cultura política y la gobernabilidad; estudios realizados, muchas veces en momentos de franca ingobernabilidad y caos en Ecuador (Burbano, 2003). Antes de pasar al Perú y al texto de Rodrigo
Montoya, quisiera agregar que me llamó mucho la atención que en su artículo publicado en ese aciago año del 2000, Andrés Guerrero afirmará no querer ceñirse a una definición de ciudadanía en términos convencionales, es decir, jurídicos y políticos; prefería concebirla, decía, "como campo de fuerza de los agentes sociales en la esfera pública y el mercado... Resituarla en un contexto de estrategias cotidianas e inmediatas de poder entre las poblaciones" (Guerrero, 2000: 12). Este tipo de argumentos será mencionado como uno de los pilares de la invitación que Assies, Calderón y Salman (2002) nos hacen para avanzar en la construcción de una "antropología de la ciudadanía”.

\section{Violencia, “ciudadanía étnica”, libertad y democracia}

En 1992, el antropólogo peruano Rodrigo Montoya publicó por vez primera "la ciudadanía étnica como un nuevo fragmento en la utopía de la libertad", texto que aparece como el tercer capítulo de su libro intitulado Al borde del naufragio (democracia, violencia y problema étnico en el Perú). En este libro Rodrigo Montoya parte de una pregunta básica: ¿es posible la construcción de una sociedad democrática en el Perú cuando lo que hemos heredado desde tiempos muy remotos, desde la derecha y la izquierda, es una tradición autoritaria? Montoya nos plantea ir más lejos del "viejo ideal de una ciudadanía simple fundada en la noción etnocéntrica y civilizatoria de igualdad". Montoya nos invita a escuchar atentamente las reivindicaciones indígenas centroandinas (ecuatorianas, peruanas, bolivianas) que exigen su derecho a ser diferentes. Estas reivindicaciones, afirmaba entonces Montoya, enriquecen "tanto la práctica como la teoría política hasta ahora 
propuestas por Occidente" (Montoya, 1992: 8).

Para demostrarnos lo anterior, Montoya parte del colapso demográfico del siglo XVI, de la formación de comunidades indígenas bajo la tutela de la Corona española, de la formación de la intelectualidad inca y de las rebeliones indígenas (por ejemplo la de 1780). Nos muestra cómo los últimos nobles incas educados se extinguieron antes de la independencia de 1821 y cómo en la nueva República, los miembros de los grupos étnicos fueron usados por el ejército realista y patriota peruano. Montoya continúa detallando el despojo y la explotación que estos grupos sufrieron a lo largo de los siglos XIX y XX a manos de caucheros, dueños de ingenios y de empresas mineras, sin olvidar las repercusiones que tuvo entre ellos la guerra contra Chile librada entre 1878 y 1884. Este proceso lleno de despojos, combates, resistencia y adaptaciones - afirmaba Montoya - terminó debilitando y aculturando a los grupos étnicos y los condujo a la pérdida de su identidad (Montoya, 1992: 50-54).

Frente a esa historia Montoya contrapone lo sucedido en Perú en el último cuarto del siglo XX cuando volvieron a aparecer en el país intelectuales indígenas, ${ }^{6}$ quienes promovieron procesos organizativos y se comprometieron a trabajar para sus pueblos. Sólo baste ver como entre 1969 y 1984 en ese país emergieron más de 50 organizaciones étnicas, muchas de ellas se agruparon en los ochenta en dos grandes centrales: la Asociación Interétnica de Desarrollo de la Selva Peruana (AIDESEP) y la Confederación de Nacionalidades Amazónicas del Perú (CONAP). Tanto organizaciones como centrales fueron poco a poco construyendo reivindicaciones novedosas (en su momento), como por ejemplo: 1) la exigencia del reconocimiento del territorio indígena; 2) la defensa de su cultura y su lengua;
3) la defensa de su dignidad; 4) y la defensa de la naturaleza de la que esos "grupos étnicos" organizados han sentido parte. Estas demandas fueron el corazón de las reivindicaciones de “ciudadanía étnica" entendidas éstas -dice Montoya (1992: 52, 72) - como el derecho a la diferencia y la libertad de afirmación de una identidad étnica particular.

Pero el proceso organizativo de los grupos étnicos no es algo generalizable a todos los indígenas ni tampoco es un producto de generación espontánea. Montoya nos explica cómo dicho proceso es sólo comprensible si atendemos las ligas históricas que hay entre los procesos y las luchas campesinas por la tierra dadas en los años sesenta (cfr. Blanco, 2006) asicomo con la ley de reforma agraria implementada en 1969, después del golpe militar de 1968 dirigido por el general Juan Velasco Alvarado, quien alentó (con palabras y hechos) la posibilidad de una gran revolución en el país, que la derecha peruana vio como "amenaza comunista” y a la que enfrentó en 1975 con otro golpe militar.

Las aspiraciones campesinas desatadas en términos agrarios hicieron crecer el trabajo organizativo indígena impulsado también por antropólogos y funcionarios comprometidos, organizaciones no gubernamentales y hasta por organizaciones religiosas, ${ }^{7}$ que dotaron de nuevas capacidades a los indígenas, quienes estaban ya formando las primeras organizaciones etnopolíticas, organizaciones clave para el desarrollo de demandas de ciudadanía étnica.

El concepto de "ciudadanía étnica" acuñado por Montoya tiene el locus anclado en la "exclusión, el desprecio y la marginación" de que han sido objeto las culturas originarias del continente. Montoya ponía especial énfasis en 
afirmar que el modelo dominante en el Perú sigue siendo colonial aunque se hayan modificado sus formas de dominación y el ejercicio de la hegemonía. Dicho modelo, señalaba Montoya, ha generado entre los indígenas una imagen negativa de sí mismos y es ahí donde "anida la amargura, el resentimiento, el odio, la rabia, los agravios" que en Perú ayudan a entender el origen de la violencia en general y de la violencia política en particular (Montoya, 1992: 24). En ese contexto, la afirmación de la identidad étnica - agregaba Montoya- se produce como respuesta a una negación (presente e histórica), como una exigencia de "reconocimiento" de un derecho colectivo no previsto en la Declaración de los Derechos del Hombre y del Ciudadano de la revolución francesa (Montoya, 1998a).

El locus y la forma narrativa en que Montoya presenta sus argumentos hacen pensar en aquellos autores que han mirado la dimensión moral de los conflictos sociales, por ejemplo, E. P. Thompson, Barrington Moore y Axel Honneth. Axel Honneth es uno de los más destacados representantes de la tercera generación de la Escuela de Frankfurt. Estudió filosofía, sociología y germanística y publicó en Alemania, el mismo año que Montoya (en 1992), su libro Kampf um Anerkennung. Zur moralischen Grammatik sozialer Konflikte (traducido al español como La lucha por el reconocimiento). ${ }^{8}$ Honneth como Haberlas, privilegia el estudio de las relaciones intersubjetivas, pero Honneth, pone todavía más énfasis en cómo ellas son "un proceso dialéctico que nos permite concebir los desarrollos y procesos sociales bajo el punto de vista de una lucha por el reconocimiento" (Comins, 1999). Siendo así, las experiencias de menosprecio pueden influir en el origen de los conflictos sociales ya que la constitución de la integridad humana depende del reconocimiento de los otros sujetos. En ese sentido la moral "comprende el conjunto de actitudes que estamos obligados a adoptar recíprocamente para asegurar en común las condiciones de nuestra identidad personal" (Comins, 1999).

Pero al definir el reconocimiento entramos en el campo fenomenológico de las ofensas morales que pueden dañar o destruir la autorrelación del individuo, es decir, ese sentimiento que cada persona tiene de sí misma respecto a las capacidades y derechos que le corresponden. Honneth parte de conceptos básicos como el amor, el respeto y la estima. Los señala como tres tipos de reconocimientos fundamentales para los individuos y los grupos, y en contraparte menciona la humillación, la denigración, la discriminación, los insultos como semillas de las demandas de justicia que articulan resistencias y revueltas en situaciones en las que ciertos caminos de la vida se han vuelto intolerables (Honneth, 1997: xix) o-agregaría-son percibidos por el individuo, o por el grupo, como intolerables.

Es ahí donde se encuentran Axel Honneth y Rodrigo Montoya a pesar de que Honneth va del proyecto metafísico hegeliano al pragmatismo naturalista de George Herbert Mead, pasando por el trabajo empírico de psicólogos, sociólogos e historiadores, mientras que Montoya se localiza más en el cruce de la antropología, la historia y la política y se autodefine seguidor intelectual de José Carlos Mariátegui. A principios del siglo XX, Mariátegui hablaba de la liberación indígena a través del proyecto socialista;" proyecto que "debía" incluir las reivindicaciones indígenas. Esto, hoy, para muchos puede ser obvio pero a finales de los veinte y principios de los treinta, las izquierdas marxistas no se caracterizaban por este tipo de planteamientos, que, a decir de Montoya (1992: 54), no tardaron en ser confrontados por "los funcionarios comunistas" de la Tercera Internacional. 
Montoya no deja de enfatizar, en su libro publicado en el 1992, que la "ciudadanía étnica" podría ser vista como un fragmento de la utopía de libertad en la que el socialismo fuera arrancado de las versiones totalitarias capitalistas y comunistas que en esos años habían mostrado su agotamiento, sobre todo, en Europa del este y Rusia. Montoya abogaba porque el socialismo fuera vivido y entendido como la "posibilidad de socializar el poder político", como la "utopía de la diversidad que no imponga nada a nadie y que deje a los pueblos ser como ellos quieren ser" (Montoya, 1992: 34). Montoya hablaba a favor de no creer que el tiempo de las utopías había llegado a su fin como afirmaban las voces triunfalistas del liberalismo, ante lo que sucedía en ese momento en el mundo. ${ }^{10}$

Pero más allá del contexto mundial, lo que movió a Rodrigo Montoya a escribir su libro Al borde del naufragio (en el que acuña el concepto de "ciudadanía étnica") fue la invitación que le hicieran sus camaradas de Izquierda Alternativa y de la Editorial Talasa del Estado Español, quienes eran unos de los muchos extranjeros preocupados por las condiciones políticas concretas por las que pasaba Perú en ese aciago año de 1992. Entonces, el país parecía ir a contracorriente al ser el único lugar en América Latina en que un partido comunista marxista-leninista no sólo sobrevivía a la crisis mundial de esa corriente política sino que amenazaba el orden establecido. Así, entre 1980 y 1992 la mitad del territorio peruano se convirtió en "zona de emergencia" y el país tenía en su haber registrados 25 mil muertos en virtud de la violencia desatada por el enfrentamiento de "dos esquemas autoritarios antidemocráticos": el de los grupos armados y el del gobierno peruano. A esto, el presidente Alberto Fujimori quiso hacerle frente en su primer período de gobierno, iniciado en 1990; en respuesta, recibió una fuerte embestida: el 26 de julio de 1992 en la calle de Tarata, en el barrio de Miraflores, en Lima, ${ }^{11}$ estallaron dos coches bombas que causaron 21 muertos, decenas de heridos e importantes pérdidas materiales. Fujimori, como parte de su campaña contra los grupos armados, logró en ese mismo julio hacer prisionero al líder del Movimiento Revolucionario Tupac Amaru (MRTA), Víctor Polay Campos y, dos meses más tarde, el 12 de septiembre, al máximo líder de Sendero Luminoso, Abimael Guzmán. Todo ello sucedía en medio de reformas estructurales económicas, del avance del narcotráfico y de la disolución por parte del propio Fujimori del Congreso de la República. ${ }^{12}$ Frente a este verdadero naufragio, Montoya veía al fondo del túnel, como luz esperanzadora, la organización, las luchas, las reivindicaciones y las movilizaciones que los grupos étnicos andinos estaban protagonizando. Ese era el marco en que Montoya hablaba de otra ciudadanía, de "doble ciudadanía", de democracia y libertad.

\section{Derechos indígenas, "ciudadanía étnica" y nación globalizada}

El antropólogo mexicano Guillermo De la Peña Topete es el tercer autor que ha acuñado, utilizado y desarrollado el concepto de "ciudadanía étnica". Guillermo De la Peña tiene una formación en la que se combinan la filosofía, la sociología y la antropología (social y de la educación). Como Guerrero y Montoya, la producción de Guillermo De la Peña es basta y diversa. En ella identificamos tres momentos (1995, 1998-1999 y 2004-2006) ${ }^{13}$ en los que el tema de la "ciudadanía étnica" aparece de la mano de 
la reflexión acerca de la naturaleza cambiante del Estado nación mexicano y de la relación (presente e histórica) de éste con los pueblos indígenas.

La reconstrucción que Guillermo De la Peña (2006a) hace de los derechos indígenas, en México, también parte de la época colonial. Al respecto afirma que en la Nueva España los naturales de estas tierras no eran propiamente ciudadanos sino súbditos de la monarquía española; súbditos tutelados agrupados en las comunidades indígenas en las que podían acceder a la propiedad colectiva de la tierra y a un sistema de autogobierno limitado. Cuando De la Peña revisa la época de Independencia, asevera que los indígenas seguían viviendo en la exclusión económica y social, a pesar de haberse efectuado el reconocimiento formal de sus derechos civiles y políticos; reconocimiento que se topó con la abolición hecha por los liberales, del régimen de autoridad y de propiedad comunal de la tierra. Con la Revolución Mexicana apareció el municipio republicano que de nuevo daba sólo cabida a una forma única de gobierno local.

Pero será la introducción del indigenismo como política de Estado en 1917, lo que favorecerá la política de "redención del indio" y la configuración de la nación mexicana como una nación mestiza, biológica y culturalmente hablando. De la Peña, en sus diversos textos (1995, 1998, 1999a y b, 2006a y b), nos explica el papel que desempeñaron en todo este proceso los antropólogos, las políticas de educación bilingüe, el Instituto Nacional Indigenista (INI), las secretarías y los funcionarios de gobierno, asicomo los congresos indigenistas y las leyes internacionales. Hasta finales de la década de los sesenta, la idea hegemónica era que el acceso irrestricto de los indígenas a los beneficios ciudadanos se daba sólo por la vía de su "aculturación" (esta idea la retoma De la Peña de los indigenistas Gonzalo Aguirre Beltrán y Alfonso Caso). Todo esto sucedía en México como parte de la construcción política de un partido de Estado que se caracterizaría por vertical, autoritario y corporativo.

De la Peña nos recuerda que a partir de 1968 las críticas al sistema político, entonces vigente, incluyeron las reclamaciones con la política indigenista, estas críticas que, surgieron desde adentro, desde los márgenes y desde afuera del propio sistema. Empezaron a oírse también, en voz de los nuevos intelectuales indígenas formados por la labor educativa del propio Estado, las iglesias, los partidos y centrales comunistas. Así, entre 1970 y 1990, en diferentes partes del país aparecieron organizaciones y movimientos urbano populares, de campesinos, de estudiantes y de indígenas; sus reclamos iban en contra de diferentes aspectos de la política social, del modelo económico o de la política autoritaria del gobierno. En el caso de los líderes y las organizaciones, había ya una demanda principal compartida: la exigencia del "reconocimiento de su realidad cultural y colectiva" (Bonfil citado por De la Peña, 2006a: 9).

Guillermo De la Peña continúa a lo largo de sus textos revisando a detalle lo que sucedió entre 1990 y 2004 en cuanto a los reclamos de los indígenas respecto a los derechos ciudadanos: para llevar a cabo tal tarea entrecruza tres ejes: 1) la formación de líderes indígenas a los que llamó "cultural brokers" o "intermediarios culturales". 2) Las reformas constitucionales en materia de cultura y derechos indígenas, sobre todo la de 1992 y la de 2001, y 3) los acuerdos nacionales y los convenios internacionales en materia de paz, autonomía y libre determinación de los pueblos indígenas. Sobre todo se detiene en la ratificación 
por parte de México del Convenio 169 de la OIT y en la firma de los Acuerdos de San Andrés entre el Ejército Zapatista de Liberación Nacional (EZLN) y el gobierno mexicano.

De la Peña (2006a: 12) reconoce la utilidad y vigencia del término "pueblo indígena" ya que éste -dice- valida a los indígenas como "sujeto de derecho" en el ámbito internacional, pero a la vez afirma que:

Conviene usar el término ciudadanía étnica para referirse a las características de los derechos ciudadanos de los miembros de un pueblo indígena al interior de un Estado nacional. Por parte del Estado, la aceptación de tales características conlleva -por el principio de equidad-la implementación de políticas de acción afirmativa que combatan la exclusión. [Supuesto esto], podemos clasificar las demandas de la ciudadanía étnica en cuatro grandes apartados: (1) la visibilidad digna, (2) el fortalecimiento y la reproducción de las expresiones culturales, (3) el desarrollo sustentable conforme a los valores propios, (4) la autoridad y la representación política diferenciada.

El contenido que De la Peña da a la "ciudadanía étnica" nos recuerda en mucho el que Montoya ha señalado para el Perú, pero existen diferencias sutiles que podrían marcarse. Por ejemplo, el mismo Montoya señaló enfáticamente que en su texto "su interés principal está en la cuestión del poder", en la relación entre culturas y la política (Montoya, comunicación electrónica, 11 de marzo de 2007). Por su parte, De la Peña pone más énfasis analítico a la dimensión de la representación politica de los indigenas cuando describe detalladamente cómo los líderes, movimientos y organizaciones indígenas de México han exigido una redistribución de poder y una verdadera participación en la toma de decisiones públicas. ${ }^{14}$ La variación en los énfasis no resulta casual si es que vemos la posición de cada uno: el Montoya de los años noventa estaba más localizado desde un marxismo crítico en relación con la antropología mientras que De la Peña hablaba más bien desde lo que se ha dado en llamar antropología sociocultural.

Por su parte, De la Peña lleva a cabo una identificación muy precisa de cuáles políticas culturales y reformas constitucionales se han realizado en México, se pregunta en qué han avanzado éstas y en qué no. De la Peña puede hacer esto porque analiza el tema particular de la "ciudadanía étnica" a lo largo de casi una década, de la misma manera Montoya regresa a este concepto en su libro publicado a finales de los noventa (Montoya, 1998b). Ahí reflexiona críticamente sobre el multiculturalismo y su relación con los derechos indígenas, humanos y ciudadanos.

Mientras que Guerrero es un historiador por excelencia ligado también al marxismo y a la sociología crítica, De la Peña da más peso al análisis antropológico de nuevas realidades con las que se enfrentan a nuevos problemas, por ejemplo mencionaba el de la representación y participación política de los indígenas migrantes internacionales. Dicha situación exige que "la ciudadanía étnica no sólo se plantee ante un solo Estado nacional sino ante todo el orden jurídico internacional en general". Desde estas circunstancias ya no podemos seguir hablando de una sola nación sino de la "nación globalizada" en la que los territorios nacionales se resignifican y se "subvierte la conexión de éstos como autocontenidos e inmutables" (De la Peña, 1999b: 23-24).

Para cerrar este apartado vale la pena señalar que De la Peña mencionó por vez primera el 
concepto de "ciudadanía étnica" en su ponencia presentada en el Simposio sobre "Ciudadanía y Exclusión en América Latina" celebrado en la New School for Social Research en abril de 1995, un año después del levantamiento de 1994 en el que el Ejército Zapatista de Liberación Nacional le declarara la guerra al gobierno mexicano. Encontramos en ello cierto paralelismo con lo que le pasó a Andrés Guerrero en Ecuador al acuñar el mismo concepto de cara al levantamiento indígena de 1990; pero además, en México el término se acuñó, como en el Perú, en medio de un contexto de violencia no sólo política sino armada.

\section{Regresemos al contexto latinoamericano}

Visto a distancia el concepto de "ciudadanía étnica" me parece que podría ser entendido como parte de un bagaje intelectual más amplio de reflexiones sobre lo que el antropólogo chileno José Bengoa ha llamado "la emergencia indígena en América Latina". José Bengoa (2000: 19) ${ }^{15}$ se refiere por "emergencia indígena" al "movimiento cultural 'panindigenista' que abarca desde el extremo sur de América hasta el norte del continente" en el que las voces de los indígenas literalmente "emergen" del silencio en el que habían permanecido; silencio roto anteriormente sólo en momentos de revueltas y rebeliones. Dicha emergencia cobró fuerza y se potenció en la década de los noventa pero se fue decantando poco a poco desde tiempos anteriores.

Con la emergencia indígena de los años noventa, para Bengoa, se reconstruyó un "nuevo discurso étnico" que puso en el centro "la demanda étnica", con la que se obligó (y se está obligando) a reelaborar las concepciones tanto de las identidades como el núcleo central de los Estados nación latinoamericanos. Reconociendo las diferencias que pueden guardar los movimientos, organizaciones y grupos étnicos que forman parte de dicha emergencia, Bengoa (2000) afirma algo que ya habían apuntado de manera particular Guerrero, Montoya y De la Peña: los líderes, organizaciones y movimientos emergentes comparten el hecho de tener en el centro de sus demandas el reclamo de reconocimiento como indígenas. ${ }^{16}$ Pero Bengoa agrega a lo anterior la sistematización y análisis comparativo de las formas concretas, los casos concretos, en que los indígenas han reinventado (en el sentido de Hobsbawm y Ranger) su identidad, en la que ponen a dialogar la tradición indígena rural con las culturas indígenas urbanas, éstas últimas están hoy urgidas por recordar. Bengoa afirma que dentro de esas demandas, ha jugado un papel central la identificación con el ideario ecologista internacional, que ha llevado a los indígenas a construir un discurso "etnoecologista" o "ecoétnico" que muchas veces va de la mano de la exigencia de autonomía, que en la práctica puede tomar muchas formas concretas pero todas -diría Bengoa (2000: 148) — remiten a "la lucha por los derechos indígenas," en el sentido de "derechos diferentes a los ... de todos los ciudadanos del país".

Es así como en América Latina se ha ido creando un pensamiento "panindígena" que tiende a dejar en un segundo plano (y hasta olvidar) las diferencias regionales y pone los acentos en las similitudes, éstas hacen posible la acción política, por ejemplo, para formar redes y frentes amplios que pueden partir desde las propias comunidades indígenas e ir más allá de las fronteras nacionales, y que permiten a los líderes indígenas de diferentes países trabajar de manera 
coordinada para hacer avanzar agendas comunes ante, por ejemplo, organismos internacionales.

Pero por más que en términos políticos esto esté sucediendo, en nuestro análisis comparativo no debemos olvidar las diferencias nacionales y regionales: en la naturaleza y en la historia de los Estados nación y en los alcances y formas organizativas de los indígenas de cada país. De entrada, al ver comparativamente a Ecuador, Perú y México, tendríamos que mencionar y tomar en cuenta que mientras, en México, la población indígena en el año 2000 ascendía oficialmente al 7.5\%, ${ }^{17}$ en Perú ésta representaba, según la fuente que se consulte, entre el $25 \%$ y el $48 \%$ de la población total. ${ }^{18} \mathrm{La}$ ambigüedad se repite en las cifras del Ecuador. Encalada, García e Ivarsdotter (1999) afirman que de los cinco censos realizados entre 1950 y 1990, sólo el primero y el último recogieron información sobre población étnica. Así, el Instituto Nacional de Estadísticas y Censos (INEC) afirma que, en Ecuador, $4 \%$ de la población total era indígena en 1990. Pero por su parte la CONAIE asevera que se trata de entre un $35 \%$ y $40 \%$, estimación que también manejan los demógrafos Alexia Peyser y Juan Chackiel (s/f).

Pero de lo que no cabe la menor duda es que Ecuador es el país con más alta densidad de población de toda América Latina, mientras que Perú ha sufrido un proceso aceleradísimo de urbanización y de aculturación de su población indígena que llega, sobre todo, a residir a Lima y sus alrededores. Algunos analistas refieren que este último fenómeno es un factor que ayuda a explicar la fuerza relativa que logran tener las organizaciones y movimientos de reivindicación étnica en el Perú. ${ }^{19}$ Otros, como Florencia Mallon, aducen razones históricas para explicar las diferencias en la formación de los Estados peruano y mexicano. Mallon nos remite al período de 1850-1910 en que el emergente Estado hegemónico en México incorporó una parte de la agenda popular mientras que el Estado peruano "nunca se estabilizó precisamente porque reprimió y marginó, una y otra vez, a las culturas políticas populares". Mallon nos muestra con lujo de detalles y desde diferentes ángulos cómo se dio esto en varias regiones y localidades mexicanas y peruanas y cómo esto "condicionó lo que ha sido posible desde entonces" en el Perú (Mallon, 2003: 557).

Y es respecto a "lo posible" que Guillermo De la Peña, en su texto publicado en 1998, reconoce las grandes diferencias que hay entre los Andes y Mesoamérica, pero a la vez señala que Ecuador y México (junto con Bolivia) son Estados en los que la reforma agraria funcionó como "espacio de reproducción del vínculo Estado-campesinos y [como] matriz simbólica donde se gestaban las imágenes bienhechoras del primero y la imagen corporativa de los segundos" (De la Peña, 1998: 39). Afirma que sólo entrecruzando los efectos de la crisis de la reforma agraria en esos países y de las políticas indigenistas, es que es posible empezar a entender las razones de fondo de la emergencia indígena de los años noventa (De la Peña, 1998: 39).

Dicha emergencia se dio en América Latina a la par de la consolidación, en la región, de las políticas neoliberales de ajuste macroeconómico y de reforma estructural que trajeron consigo polarización, empobrecimiento de las mayorías y retiro del Estado de sus funciones tradicionales (Dávalos, 2005b). Para varios autores existen otros elementos que ayudan a explicar la "emergencia indígena" de los años noventa. Primero se puede mencionar la crisis profunda en que cayó la idea y las prácticas hegemónicas 
Xochitl Leyva Solano

de ciudadanía y democracia, que sostenían los gobiernos constitucionales latinoamericanos en la segunda mitad del siglo XX (Bengoa, 2000; Dávalos, 2005b). En segundo lugar, podemos afirmar que el surgimiento de nuevos movimientos sociales en América Latina (entre ellos el indígena) también fue posibilitado por el término de la Guerra Fría y de su esquema bipolar en el que sólo cabían el "comunismo" y el "capitalismo". $\mathrm{Y}$ en tercer lugar, pero no por ello menos importante, está la globalización que -como dice Bengoa- en todo el mundo parece llevar consigo la revalorización de las relaciones sociales y de las identidades locales.

En el capítulo tres de su libro, Bengoa nos habla de cómo la "emergencia indígena en América Latina” tiene un pasado reciente, en los años ochenta cuando nacieron organizaciones indígenas ligadas a las iglesias y a los organismos no gubernamentales. Entre 1985 y 1992, se puede hablar de un segundo periodo que gira en torno a la "celebración" y las contra-celebraciones de los "500 años del Descubrimiento de América" (Plascencia, 1996; Sarmiento, 1998; Bengoa, 2000). Una tercera etapa se identifica a raíz de los levantamientos de Ecuador (1990) y de Chiapas, México (1994). José Bengoa terminó de escribir su libro en el año 2000, quizá por eso es que ya no pudo incluir en él, por ejemplo, las masivas movilizaciones de 2003 en Bolivia, en contra de las políticas neoliberales implementadas por el presidente Gonzalo Sánchez de Lozada (Ticona, 2005) ni la llegada, en 2006, a la presidencia boliviana del aymara líder sindical Evo Morales ni las masivas movilizaciones sucedidas entre marzo y abril de ese mismo año en Ecuador, en contra de la firma del Tratado de Libre Comercio con Estados Unidos de Norteamérica. Quizá estos años y estos hechos podrían marcar la cuarta etapa de la "emergencia indígena" que está en marcha y que presenta nuevos retos no sólo a los indígenas sino a las sociedades y naciones latinoamericanas en su conjunto.

\section{E1 concepto de "ciudadanía étnica", ¿herramienta heurística?}

Después de revisar detalladamente cómo tres autores de tres países diferentes han dado vida al concepto de "ciudadanía étnica", parecería lógico afirmar que éste puede ser concebido como una herramienta heurística, parte de un modelo interpretativo más amplio que nos ayude a entender y explicar "la emergencia indígena en América Latina” y más allá de ella, las relaciones entre los Estados, la nación y los pueblos indígenas. Dicho modelo no existe como un todo coherente y articulado, compendiado en un solo libro o en una sola persona, por el contrario, se compone de muchos diálogos a diferentes niveles. Desde cierto ángulo, podríamos decir que el concepto de "ciudadanía étnica" surge de la convergencia del pensamiento y la acción de las organizaciones y movimientos indígenas con intelectuales y académicos, indígenas y no indígenas, especialistas todos ellos en el tema y en la región (Leyva, 2001). En otro sentido, dicho concepto nos remite directamente al campo de la ciudadanía sustantiva, sociocultural y activa y nos introduce en el debate académico-político más amplio de la "ciudadanía cultural” y los derechos diferenciados.

Para autores como Stinchcombe (1975), Brubaker (1992) y Somers (1999), la ciudadanía de los tiempos modernos tiene componentes fundamentales, como: la pertenencia, la participación, la asociación, la inclusión/exclusión, la identidad nacional y sobre todo la soberanía 
de ley garantizada constitucionalmente. Steven Luckes y Soledad García (1999) agregan que hoy el desarrollo de la "ciudadanía postnacional" está poniendo en entredicho el vínculo entre ciudadanía y nacionalidad, pero más allá de esta realidad, Luckes y García se empeñan en señalar que su campo de trabajo privilegiado es el de la "ciudadanía sustantiva". Este es también el campo en que ubicamos a los estudiosos de la "ciudadanía étnica", en la medida en que todos ellos hablan de la ciudadanía como "resultado de conflictos sociales y luchas por el poder que se producen en coyunturas históricas concretas" (Luckes y García, 1999: 1). Estas luchas pueden ser -agregan-de clase, étnicas o geopolíticas. Desde esta perspectiva, se privilegia lo "que ha significado la ciudadanía en la práctica en diversas sociedades contemporáneas" (Luckes y García, 1999: 2).

Al ver los comparativamente podría atreverme a afirmar que el interés en las prácticas culturales, políticas y de poder llevó (por separado) a Guerrero, Montoya y De la Peña a dar centralidad en sus análisis a los asuntos morales y éticos y a las formas de participación activa para la realización o cumplimiento de esos valores. Una perspectiva como ésta coloca a los autores entre aquellos estudiosos que analizan la "ciudadanía sociocultural" antes que la "ciudadanía formal" (cfr. Laponce, 1995), y entre aquellos que se preguntan por el sentido de participación directa en los asuntos públicos ("ciudadanía activa") en vez de verla como la "titularidad para recibir bienes y servicios garantizados por derechos" ("ciudadanía pasiva") (Crouch, 1999: 258-259).

El interés en la "ciudadanía activa" tiene una larga historia en América Latina. No pretendo abordarla en este texto pero sí señalar que dicha historia tiene uno de sus puntos de partida en los trabajos en los que se estudien la democracia y los movimientos sociales. ${ }^{20}$ Por el momento, me detendré sólo en el trabajo de la socióloga argentina Elizabeth Jelin (1987, 1993, 1994, 1996,) quien desde tiempos muy tempranos se preguntó por la democracia y la ciudadanía a partir del el estudio de la expansión de las políticas públicas y el desarrollo de los movimientos sociales basados en las demandas de campesinos, trabajadores, mujeres, jóvenes y residentes de barrios populares. Con su trabajo, Jelin rechazó las visiones universalistas de los derechos y demostró cómo, en Argentina y en América Latina, la ciudadanía es ante todo un producto fortuito de las luchas populares por la dignidad y por el "derecho a tener derechos" (cita a Arendt y Lefort); se trata de una empresa colectiva culturalmente significativa que conduce a una "práctica conflictiva vinculada al poder, que refleja las luchas acerca de quiénes podrán decir qué en el proceso de definir cuáles son los problemas comunes y cómo serán abordados" (Jelin, 1996: 116).

Al referirme al significado cultural de la ciudadanía se entra en el campo resbaloso que opone ciudadanía a cultura. En ese contexto ciudadanía implica "igualdad en cuanto conjunto de elementos que otorgan derechos iguales, uniformes a todos los participantes en el Estado y les da obligaciones uniformes" (Villoro, 2002: 36), mientras que cultura presupone diversidad y alude a alteridades construidas socialmente que pueden ser usadas para el reclamo de derechos diferenciados.

Pero esta oposición teórica cobra sentido práctico en la política si vemos que son algunos de los intelectuales latinos de los Estados Unidos quienes empiezan a hablar de la "ciudadanía cultural” (Rosaldo, 1985, 1994, 1997) para referirse a una variedad de prácticas 
socioculturales, con las cuales, tomadas en conjunto, se reclama el establecimiento de un espacio social distintivo. Son prácticas que en Norteamérica han contribuido al desarrollo social y político de los latinos y a la emergencia de una conciencia latina particular que obliga al Imperio (y no sólo a la nación) a repensar el acuerdo normativo y cultural vigente..$^{21}$ Visto así, se puede decir que tanto a la "ciudadanía cultural" como a la "ciudadanía étnica" les estructura un discurso y una práctica de resistencia cultural que exige (demanda, manda) la reconfiguración de los espacios públicos.

\section{Aportes, límites y pendientes}

Los conceptos de "ciudadanía cultural" y de "ciudadanía étnica" vienen a enriquecer los postulados clásicos que el sociólogo inglés T. H. Marshall hiciera en 1949. Marshall desde una visión más bien evolucionista ${ }^{22}$ planteaba que la ciudadanía era un estatus que involucraba el acceso a varios derechos y poderes, un estatus que buscaba que todos los hombres fueran iguales sin privilegio de clase hereditario. Marshall (1964), en su momento, habló del surgimiento de los derechos ciudadanos como la consecuencia casi innevitable de la modernización industrial de Inglaterra. Pero en ese recuento dejó siempre fuera la posibilidad de que los escoceses y los galos se pudieran también expresar al nivel de los ingleses (todos ellos parte de la Gran Bretaña). Marshall ni siquiera se planteó la diversidad cultural y étnica del Reino Unido como punto de partida o al menos como punto de reflexión. Sí en cambio aportó una triada aún válida y útil. ${ }^{23}$ Me refiero a los tres componentes principales que en Occidente se consideran la base de la ciudadanía moderna: el civil (que se refiere a las libertades individuales), el político (que remite a la participación política) y el social (que incluye derechos relacionados con el trabajo, la educación, la vivienda, la salud y las prestaciones). Tríada a la que los nuevos movimientos sociales se han encargado de agregar los reclamos sobre los derechos culturales, étnicos, de género, binacionales, ecológicos y reclamos de derechos sobre la propiedad intelectual de los pueblos indígenas.

Pero si el pasado más cercano del estudio de la ciudadanía lo ubicamos en el campo de las clases sociales y el desarrollo industrial capitalista, hoy la reflexión sobre ciudadanía está posicionada en una arena diferente: la de la democracia, el Estado plural y la globalización. Respecto a la relación entre la democracia y el Estado plural, el filósofo mexicano Luis Villoro afirma que hoy los Estados nación tienen graves problemas para hacer conciliar dos exigencias contrapuestas: el respeto a la pluralidad de los pueblos que integran ese Estado y la unidad y colaboración entre ellos. En ese marco, las demandas de los movimientos indígenas latinoamericanos más que reclamar la soberanía política frente al Estado nación dominante, exigen la transformación de éste Estado nación-homogéneo en Estado plural, en el que la ciudadanía no debería ser excluyente de ninguna pertenencia a ninguna nacionalidad contenida en ese Estado. Siendo así, la noción de ciudadanía tendría que depurarse en el sentido de no representar sólo los fines, valores y concepciones del grupo o nación dominante. La "ciudadanía depurada" de todo carácter nacional estatuye una igualdad básica entre todos los grupos diferentes de un solo Estado y supone un convenio entre todos ellos (Villoro, 2002). Villoro incluso llega a proponer la categoría "ciudadanía 
depurada" como una alternativa y por tanto una forma de crítica directa a las nociones de “ciudadanía diferenciada” (Kymlicka, 1996) y de “ciudadanía étnica” (tomada de De la Peña). Al respecto, Villoro afirma:

Ambas propuestas tienen, sin duda... el acierto de dar satisfacción a las legítimas reivindicaciones de los grupos con culturas e identidades diferenciadas. Sin embargo... me parece que logran esa ventaja a costa de mantener una concepción de la ciudadanía que puede funcionar como un instrumento de exclusión... En efecto la ciudadanía diferenciada razona generalizando a todo grupo o nación, la práctica de otorgarle caracteres nacionales que realiza el estado-nación homogéneo respecto de una nación hegemónica. Si lo mismo que el estado-nación homogéneo incluye dentro de su idea de ciudadanía caracteres de su nación, una ciudadanía diferenciada o étnica incluiría también caracteres de la etnia o de la nación diferenciada en la idea de ciudadanía, y esto me parece que da lugar a problemas. [Ambas propuestas] no parten además, de la distinción conceptual... entre derechos anteriores al estado plural y derechos promulgados por éste... Una ciudadania diferenciada o étnica correría el riesgo de favorecer la tendencia de las partes a entrar en rivalidad con las demás en el todo... correría el riesgo de subordinar los fines comunes a los intereses de grupos diferenciados (Villoro, 2002: 35).

Las idea críticas de Villoro nos recuerdan las de Leyva (2005) quien menciona que en México en la práctica existe una traspolación entre "lo étnico" y "lo indígena" que conduce a hablar de "ciudadanía étnica” prácticamente reducida a los "derechos diferenciados de los ciudadanos indígenas" cuando los reclamos de ciudadanía étnica en otras partes del mundo podrían incluir a más y diferentes grupos socioculturales que politizan su identidad. Claramente Leyva señala que en México esta traspolación tiene una historia colonial bien definida y explicable que puede argumentarse pero que en la vida cotidiana puede crear problemas como los argumentados por Villoro.

La crítica de Luis Villoro al concepto de "ciudadanía étnica" podría ser respaldada con ejemplos concretos pero también con otros ejemplos, refutada. Primero, pensemos en el caso guatemalteco y en los reclamos de "ciudadanía étnica" hechos por el Movimiento Maya en las últimas tres décadas del siglo XX. Dichos reclamos han levantado reacciones contundentes entre los ladinos (Morales, 2000). En el marco del VI Congreso de Estudios Mayas celebrado en ciudad de Guatemala en agosto de 2005, despúes de escuchar una ponencia sobre el Movimiento Maya (su historia y sus demandas) una mujer me comentó: "bueno pues si ellos tienen derechos especiales nosotros también los queremos como ladinos que somos, porque nosotros también tenemos una identidad, una historia y una cultura”. El tono del comentario era de gran molestia y de un cierto grado de indignación. Más allá de que alguien pudiera considerar que la "cultura ladina" ha sido históricamente la dominante en Guatemala o al menos dominante frente a la maya-indígena, lo que el ejemplo nos lleva a pensar es que la existencia de ambos discursos refuerzan la idea de que el problema central de Guatemala es la confrontación "ladino versus indígena". ${ }^{24}$ Idea bipolar popularizada sobre todo por los estudios culturalistas norteamericanos. Ya los antropólogos guatemaltecos José Alejos (1992) y Ramón González Ponciano (1992) han explicado 
que dicha concepción no deja ver los problemas de fondo en torno a la redistribución (del poder, de la tierra, del dinero) y a la discriminación y el racismo que van mucho más allá de las "relaciones interétnicas" y el reconocimiento.

El mismo Luis Villoro se refiere a los Acuerdos de San Andrés, firmados entre el gobierno mexicano y el EZLN el 16 de febrero de 1996, como un ejemplo concreto que reconoce la necesidad de otorgar derechos comunes de ciudadanía a todo ciudadano (más allá de la etnia, la raza, el color) a la par que otorgar derechos diferenciados pactados frente al Estado con base en la autonomía de cada pueblo (Villoro, 2002: 35). Sin duda, como afirma Villoro, en dichos Acuerdos se avanza pero al final vuelve a prevalecer el "principio jurídico fundamental de la igualdad de todos los mexicanos ante la ley y los órganos jurisdiccionales" (Ce Acatl 1996: 3839); con ello se impide que los derechos diferenciados se reconozcan como pasó en la "Ley de Derechos y Cultura Indígena del Estado de Chiapas" (cfr. Leyva, Olvera y Burguete, 1999).

Pero quizás la manera más concreta de ver cómo el concepto de "ciudadanía étnica" ha mostrado sus bondades es mediante la mención de que ya existe un número importante de estudiosos (en su mayoría antropólogos) que lo han integrado a su análisis tanto de Guatemala (Bastos, 1997) como de México (Harvey, 1998; Rojas Cortés, 2000; Zárate, 2002; García Rojas, 2003; Leyva, 2002 y 2005; Navarro, 2006; Buenrostro en prensa).

Llama la atención que Santiago Bastos (1997), Neil Harvey (1998) y Xochitl Leyva (2002, 2005) utilizan la noción de "ciudadanía étnica" nuevamente en contextos donde los movimientos indígenas están envueltos en conflictos armados, represión y alta militarización. Aunque es claro que lo ocurrido en Guatemala está lejos de lo acontecido en Chiapas-México, estos autores comparten el haber escrito sus reflexiones después de la firma de los acuerdos de paz y el poner el centro de su atención en las demandas que enarbolan las organizaciones indígenas (chiapanecas-mexicanas) y el Movimiento Maya, en el sentido de demandas "étnicas" que remiten a un principio de reconocimiento, de derechos diferenciados y de reestructuración del orden normativo de Guatemala y México.

Los autores mexicanos que en sus análisis recurren al concepto de "ciudadanía étnica," son principalmente seguidores de la propuesta conceptual de Guillermo de la Peña. Por su parte, Eduardo Zárate (2002) lo hace cuando se pregunta por la posibilidad real de inserción de las comunidades indígenas en el mundo contemporáneo como sujetos plenos con personalidad jurídica propia. Zárate aboga por una ciudadanía que no sólo sea compensatoria sino que reconozca la modernidad y la actualidad de las comunidades indígenas construidas a través de la reinvención constante de la comunidad. Esta modernidad muchas veces -agrega Alejandra Navarro (2006) - exige un reconocimiento de doble sentido: de afuera hacia adentro y hacia el interior de las comunidades. Navarro también utiliza el concepto "ciudadanía étnica" al estudiar a un grupo de defensores indígenas comunitarios de Chiapas, quienes buscan, con su quehacer cotidiano, transformar las percepciones del "ser indígena" y las relaciones entre indígenas y no indígenas en los ámbitos institucionales y no institucionales de la impartición de justicia. Angélica Rojas Cortés (2000) por su parte, realizó un estudio en el campo institucional, en particular, analizó la escuela secundaria comunitaria a través de la cual los huicholes 
refuerzan su conocimiento de los códigos de la sociedad mayor, mismos que utilizan para exigir el cumplimiento de planes y programas educativos que les permiten hacer avanzar sus demandas de "ciudadanía étnica". En ese sentido, Manuel Buenrostro (en prensa) nos explica que los jueces mayas de Quintana Roo también podrían ser vistos como ciudadanos que de manera cotidiana y sin echar mano de la movilización, buscan el reconocimiento de lo que llaman el "derecho maya." Derecho que a través de esos reclamos, deja de ser sólo una reforma "desde arriba" para abrir un intersticio a favor de la construcción de la agencia (agency) maya. Pero serán los reclamos y estrategias cotidianas de los ñahñús de Querétaro y los mixtecos de Oaxaca, quienes llegan a trabajar a Nuevo León, motivo del estudio de Gustavo García Rojas (2003). Este autor nos muestra las particularidades que poseen dichas demandas en plena economía neoliberal y fronteriza.

Después de realizar las lecturas, conexiones y reflexiones que me permitieron escribir este artículo, me parece justo señalar que el concepto de "ciudadanía étnica" ha seguido un camino concreto y real por el que hemos transitado para abonar en la construcción de la "antropología de la ciudadanía”. Y lo digo pensando en las bondades que John Glehill (2002: 510) le ve a los estudios antropológicos, a los cuales llama estudios "desde abajo". Estos — dice Gledhill- "permiten poner en tela de juicio las expectativas utópicas que a veces surgen de reflexiones filosóficas o meramente teóricas". Creo que en gran parte eso hicieron los pioneros que acuñaron el concepto y eso están haciendo sus seguidores.

Pero a pesar de reconocer esto como un avance, siempre quedará sobre la mesa la crítica de todos aquellos estudiosos de la "ciudadanía formal", quienes exigen que se señale de forma concreta cómo se dará forma jurídica a todos esos reclamos de derechos diferenciados. Pero como dice Santiago Bastos (1997), la construcción de las demandas de "ciudadanía étnica" está dándose, es un proceso inacabado. Ello pone permanentes retos analíticos y políticos no sólo a los estudiosos del fenómeno sino a los actoressujetos de esas demandas, quienes se enfrentan a los proyectos neoliberales que recorren todos los países latinoamericanos, los que $\mathrm{p}$ los derechos civiles, restringen los políticos, abrevian los sociales (Willem, Calderón, Salman, 2002: 21) y fomentan los culturales, siempre y cuando no pongan en jaque al sistema.

En construcción desde América Latina. Última idea

A manera de conclusión, resumo mis argumentos centrales y agrego una última idea. En este artículo me he ocupado de reflexionar en torno a un tipo particular de ciudadanía: la sociocultural, sustantiva y activa. Después de un breve recuento de lo que ha pasado en Ecuador, Perú y México, hemos visto que existen reclamos y demandas de comunidades, organizaciones y movimientos indígenas que pueden ser llamados de "ciudadanía étnica". Dichos reclamos no sólo están cuestionando las raíces liberales de los Estado nación latinoamericanos sino también nos están obligando a revisar nuestras categorías y sistema de pensamiento.

La noción de "ciudadanía étnica" se ha ido estructurando más que como un modelo interpretativo acabado, como una herramienta heurística que, propongo aquí, es parte de un modelo más amplio. Dicha herramienta resalta la dimensión histórica, política, cultural, ética y moral de la ciudadanía sustantiva aunque como 
ya han dicho Bastos (1998), Villoro (2002) y Leyva (2005), el concepto necesita ser trabajado aún más.

El lector se habrá dado cuenta de mi insistencia en que los movimientos referidos son latinoamericanos y los estudiosos mencionados son lationoamericanos y los gobiernos son lationamericanos. La insistencia no sólo tiene que ver con ubicar geográficamente los procesos a los que me refiero, tiene también que ver con una reflexión más vieja que como bien apunta Anibal Quijano (1999) gira en torno a la colonialidad del poder, la cultura y el conocimiento en América Latina. Más recientemente Susana Narotzky (2005) y varios miembros de la Red de Antropologías Mundiales (RAN-WAN) ${ }^{25}$ se preguntaban de nuevo si es posible pensar fuera de los discursos hegemónicos. No pretendo cerrar este artículo respondiendo a la pregunta pero sí quiero señalar que me parece que los pioneros de la ciudadanía étnica aquí revisados y citados, nos muestran de manera concreta con su trabajo que es posible la producción excéntrica de conceptos y teorías interpretativas que comparten una característica peculiar: el estar "volcados hacia el estudio de sus propias realidades, como un acto político en sí mismo centrado en las transacciones sociales entre y en el interior de los pueblos... situando la diversidad permanentemente como objeto político y base del quehacer antropológico" (Ramos cit., en Narotzky, 2005). Sin duda que esta última idea daría para armar otro artículo pero por el momento aquí termino.

\section{Notas}

1 Los interesados en profundizar en el estudio de los movimientos indígenas en América Latina y su relación con los Estados, las naciones y la sociedad más amplia pueden consultar los siguientes textos: Díaz Polanco, 1985, 1987, 2004; Cardoso de Oliveira, 1990; Bartolomé y Barabas, 1998; Assies, Van der Haar y Hoekema 1999; Gros, 2000; Bengoa, 2000; Stavenhagen, 2000; Calderón, Assies y Salman, 2002; Bello, 2004; Dávalos, 2005a y b; Toledo, 2005; Pacari, 2006; Gutiérrez y Escárzaga, 2006; Leyva, Burguete y Speed, en prensa.

${ }^{2}$ Agradezco a mi colega y amigo Santiago Bastos el haberme sacado de esa ignorancia y haberme recomendado enfáticamente leer a fondo a Guerrero y a Montoya.

${ }^{3}$ Es hasta su texto publicado en 1999a que Guillermo De la Peña retoma el concepto de "sujetos indios", acuñado en 1990 por Andrés Guerrero en su estudio histórico de las distintas formas de dominación de los indígenas del Ecuador.

${ }^{4}$ En su texto publicado en 2000, Andrés Guerrero trata más a detalle las cuestiones de ciudadanía en el siglo XIX.

${ }^{5}$ CONAIE quiere decir Confederación de Nacionalidades Indígenas del Ecuador y fue creada en 1986, aglutina 14 nacionalidades indígenas (Macas, 2005). El proyecto político de la CONAIE propugna la consolidación de un estado plurinacional y de una sociedad intercultural (Tibán y García, en prensa).

${ }^{6}$ Algunos egresados de las universidades, otros, producto de procesos informales de educación promovidos por las iglesias, los organismos no gubernamentales, los antropólogos comprometidos, los funcionarios comprometidos, etcétera.

${ }^{7}$ Rodrigo Montoya (1992: 66) menciona, por ejemplo, el papel que desempeñó el Instituto Lingüístico de Verano en la selva amazónica en cuanto a la educación informal de los indígenas, pero a la vez señala cómo se dieron rupturas con dicho Instituto, las que permitieron a los indígenas amazónicos caminar hacia el desarrollo étnico, autónomo y laico.

${ }^{8}$ En inglés se publica en 1996 y es traducido al español en 1997.

${ }^{9}$ José Bengoa (2000: 224) al hablar de Mariátegui afirma que éste ve la reconstrucción de lo indígena, de "la andinidad" en el socialismo, desde el movimiento comunista internacional, desde la revolución. Para Bengoa esto es "un paso más en el indigenismo", en su variante de izquierda que se mantiene marginal al 
indigenismo de carácter más oficial o integracionista, con el cual finalmente nunca rompen, porque - agrega Bengoa- les unía finalmente la "defensa del indio" (226). Mariátegui fundó en 1928 el Partido Socialista en el Perú, el que se convirtió en 1930, en Partido Comunista.

${ }^{10}$ Recuérdese que la unificación de las dos Alemanias se inicia con la caída del muro de Berlín en 1989, y que exactamente cuando escribía Rodrigo Montoya, la Unión Soviética ya se había desintegrado, Yugoslavia había desaparecido y los checos se habían separado de los eslovacos.

${ }^{11}$ Montoya (1992: 76) describe el barrio de Miraflores como barrio símbolo del poder oficial, colonial y limeño.

${ }^{12} \mathrm{~A}$ este período se le conoce como la Crisis Constitucional de 1992 y popularmente como el autogolpe. El episodio desencadenaría acciones militares contra Fujimori, quien se refugió en la embajada de Japón denunciando un intento de asesinato y al poco tiempo constituyó un Gobierno de Emergencia y Reconstrucción Nacional, con el que convocó a elecciones para un Congreso Constituyente Democrático que sancionó posteriormente la Constitución de 1993. El carácter autoritario de todas estas medidas va a ser una crítica constante al presidente Alberto Fujimori.

${ }^{13}$ Ver De la Peña 1995, 1998, 1999a y b, 2006a y b.

${ }^{14}$ Como ejemplos, remite a las demandas del Congreso Nacional Indígena o a las de los zapatistas en las mesas de diálogo celebradas en San Andrés Larrainzar (Chiapas) en 1996.

${ }^{15}$ Como el lector podrá notar, el análisis contextual de los autores sólo lo he llevado a cabo para los pioneros, sin embargo, en sentido estricto, cada autor mencionado en este artículo merecería una contextualización similar de su obra, de sus aportes y limitaciones (o al menos las críticas que otros han hecho a su obra). Ello se vuelve indispensable sobre todo cuando citamos, por ejemplo, en Chile o en México a autores sumamente polémicos por sus planteamientos político-académicos.

${ }^{16}$ Bengoa (2000) señala cómo en los años setenta los indígenas no hablaban de autonomía sino que reclamaban la tierra.

${ }^{17} \mathrm{INEGI}, 2000$.

${ }^{18}$ Esta cifra pertenece al Banco Mundial y fue citada en la página 48 del Informe Nacional de Desarrollo Humano del
PNUD-Guatemala publicado en el 2005. En otras fuentes se habla de que en 1981 los indígenas en Perú representaban un $27 \%$. Buscando en un diccionario (ESPASA, Madrid, 1993) se encontró la cifra de $47 \%$ para 1990. Curiosamente, en la página web del gubernamental Instituto Nacional Estadísticas e Informática (INEI) no existe posibilidad alguna de obtener este tipo de información, pues la identidad étnica no se maneja como un indicador medido.

${ }^{19}$ Es bastante común encontrar en la bibliografía quienes se preguntan: ¿por qué en el Perú no hay un "movimiento indígena" de la envergadura del ecuatoriano? Hasta muy recientemente el "movimiento indígena" por excelencia era el existente en Ecuador, éste se veía como el "movimiento modelo" con articulación desde la base hasta los líderes, con capacidad de movilizar no sólo a sus bases sino a otros sectores de la sociedad, con estrategias de negociación ágiles, con alianzas amplias, con trabajo en el campo comunitario, regional, nacional y hasta electoral, con un proyecto de nación incluyente que resulta atractivo no sólo para los indígenas, etcétera, Todo esto está a revisión en el propio movimiento ya que las coyunturas de 1998, 2000 y 2002 han dejado claras lecciones (cfr. Macas 2001). De acuerdo con Pablo Dávalos asesor de la CONAIE, en 1998 el movimiento indígena, después de haber participado en la destitución del presidente en turno, logra presionar para que se convoque a una Asamblea Nacional Constituyente, la cual finalmente termina reforzando a Estado neoliberal ecuatoriano a pesar de que se avanza en el reconocimiento de derechos constitucionales colectivos específicos. En el año 2000, el movimiento indígena en alianza con un grupo de militares y en convergencia coyuntural de intereses con la burguesía financiera, logra derrocar al presidente en turno, quien estaba a favor de la dolarización de la economía ecuatoriana y de la implementación de un paquete de ajuste económico perjudicial para las mayorías. Si bien la movilización logró destituir al presidente no logró parar la dolarización. Finalmente, en 2002, se dio el triunfo electoral del coronel Lucio Gutiérrez, quien contó con el apoyo del movimiento indígena. Se trataba del mismo militar que había sido aliado estratégico en la coyuntura anterior, sin embargo, la economía de su nuevo gobierno quedó finalmente en manos del Banco 
Xochitl Leyva Solano

Mundial y poco se avanzó en los cuatro ministerios ocupados por dirigentes indígenas miembros del movimiento indígena. Dicho movimiento trató de ser cooptado y desarticulado desde el propio gobierno (Dávalos, 2006).

${ }^{20} \mathrm{Al}$ respecto se puede ver la obra de David Slater, Arturo Escobar, Sérgio Baierle, Judith Hellman, Sonia Alvarez, Eveligna Dagnino, Escobar y Alvarez, Alvarez y Dagnino y Jelin y Hershberg. Las citas se pueden encontrar en Escobar, Álvarez y Dagnino 2001.

${ }^{21} \mathrm{El}$ concepto "ciudadanía cultural” fue sugerido por el antropólogo chicano Renato Rosaldo cuando trabajaba en su libro Culture and Truth (1989) y desde su temprano artículo “Assimilation Revisited” (1985). Más tarde, en octubre de 1987, el concepto fue trabajado interdisciplinariamente por el "Latino Cultural Studies Working Group of the Inter-University Program for Latino Research (IUP)". Una revisión de los debates y resultados de investigación de este grupo pueden ser consultados en Flores y Benmayor (1997).

${ }^{22}$ No hay texto referido a la ciudadanía que no mencione los postulados de T.H. Marshall. Pero además de retomarlo como punto de partida obligado, la mayoría de los autores hace una crítica puntual a su visión evolucionista, etnocéntrica y monocultural. Ver algunas de las referencias y críticas en Jelin 1996, Cortina 1998, Procacci 1999, Somers 1999, Luckes y García 1999, De la Peña 1999a, Crouch 1999, Assies, Calderón y Salman 2002, Gledhill 2002 y Ceja 2005.

${ }^{23}$ Este artículo no tiene como fin desarrollar el pensamiento de T. H. Marshall a fondo pero si señalaré brevemente cómo él afirmaba que en los pueblos medievales pudo haber habido ejemplos de genuina e igualitaria ciudadanía, pero los derechos y deberes específicos eran estrictamente locales mientras que la ciudadanía que él estudia es la que por definición es nacional, para ello nos remite al siglo XVIII y al nacimiento de los derechos civiles modernos. Más tarde, en el siglo XIX, los derechos políticos emergen como parte de las demandas de la clase trabajadora $\mathrm{y}$, en el siglo XX, los derechos sociales -dice- se han convertido en un componente mayor de la definición de ciudadanía (Marshall, [1949] 1964).

${ }^{24} \mathrm{Al}$ respecto Santiago Bastos (1997) nos dice que: "En una investigación realizada en tres ámbitos espaciales del área metropolitana de Guatemala, sólo un 20\% de quienes no se identificaron como indígenas lo hicieron como ladinos. Un grupo menor incluso se identificó como "indígena”, por que "en Guatemala todos lo somos”. El resto tendía más a la identificación negativa de "no indígenas" o acudía a referentes espaciales: “costeño”, “capitalino”, “oriental”. Y también habría que recordar a esa parte de la oligarquía que según Martha Casaus no se identificaba en absoluto con los ladinos, lo que trae a colación a los criollos, ese tercer grupo de la etnicidad guatemalteca que tan sabiamente supo 'quitarse de en medio' a finales del XIX”.

${ }^{25} \mathrm{~A}$ los interesados en la construcción de las antropologías periféricas, las antropologías mundiales y las otras formas de producción del conocimiento más allá del académico, se les recomienda ver la página web de la Red de las Antropologías Mundiales (en inglés World Anthropologies Network): http://www.ram-wan. net/html/home e.htm

\section{Bibliografía}

Adrianzén, Alberto, Jean Miel Blanquer, Ricardo Calla, Carlos Iván Degregori, Pierre Gilhodes, Andrés Guerrero, Patrick Husson, Jean Pierre Lavaud, Jorge León, Rodrigo Montoya, Daniel Pécaut, Eduardo Pizarro y Alberto Rocha, 1993, Democracia, etnicidad y violencia politica en los paises andinos, Instituto Francés de Estudios Latinos e Instituto de Estudios Peruanos, Lima.

Alejos, José, 1992, “GAM: Indígenas y derechos humanos en Guatemala", en Memorias del Primer Congreso Internacional de Mayistas, UNAM, México, Tomo I, pp. 450-467.

Assies, Willem, Marco A. Calderón y Ton Salman, 2002, "Ciudadanía, Cultura Política y Reforma del Estado en América Latina”, en Marco A. Calderón, Willem Assies y Ton Salman (editores) Ciudadanía Cultural, política y reforma del estado en América Latina, El Colegio de Michoacán y el Instituto Federal Electoral de Michoacán, Zamora, Michoacán, pp. 17-58.

Assies, Willem, Gemma van der Haar y André Hoekema (editores), 1999, El reto de la diversidad. El Colegio de Michoacán, A.C., Zamora, Michoacán.

Bartolomé, Miguel A., y Alicia Barabas, 1998, Autonomías Étnicas y Estados Nacionales, CONACULTA y el INAH, México. 
Bastos, Santiago, 1997, ¿En busca de la ciudadanía étnica? Reflexiones en torno al Movimiento Maya y al Acuerdo de Identidad y Derechos de los Pueblos Indígenas. Ponencia presentada en el II Congreso de Estudios Mayas, en la Mesa "La reformulación de la nación en el marco de los Acuerdos de Paz", Universidad Rafael Landívar, Ciudad de Guatemala del 6 al 8 de agosto. Un texto más reciente que también se puede consultar es: Santiago Bastos y Manuela Camus, 2004, "Multiculturalismo y Pueblos Indígenas: reflexiones a partir del caso de Guatemala", en Revista Centroamericana de Ciencias Sociales, No. 1, FLACSO, Costa Rica, pp. 106-117.

Blanco, Hugo, 2006, "Entrevista a Hugo Blanco", en Corriente[a]lterna, 10 de noviembre, tomado de http://www.espacioalternativo.org/

Bengoa, José, 2000, La emergencia indígena en América Latina, Fondo de Cultura Económica, Chile y México.

Bello, Álvaro, 2004, Etnicidad y ciudadanía en América Latina. La acción colectiva de los pueblos indígenas. CEPAL, Santiago de Chile.

Brubaker, R. 1992, Citizenship and Nationhood in France and Germany, Harvard University Press, Cambridge.

Burbano Lara, Felipe, 2003, "Democracia, cultura política y gobernabilidad. Los estudios en los años noventas”, en Felipe Burbano Lara (comp.) Antología. Democracia, gobernabilidad y cultura politica, FLACSO Sede Ecuador, Quito, pp. 13-66.

Buenrostro, Manuel, en prensa, "Pueblos indios y ciudadanía. El caso de los mayas de Quintana Roo”, en Mayas Modernos, Universidad de Quintana Roo y Plaza y Valdés.

Calderón Marco A., Willem Assies y Ton Salman (editores), 2002, Ciudadanía Cultural, politica y reforma del estado en América Latina, El Colegio de Michoacán y el Instituto Federal Electoral de Michoacán, Zamora, Michoacán.

Ce Acatl, 1996, Los primeros Acuerdos de Sacam Ch'en. Compromisos propuestas y pronunciamientos de la Mesa de Trabajo 1: Derechos y Cultura Indígena. Número Especial 78-79, Marzo 11- Abril 19.

Ceja, Jorge, 2005, "Democracia y ciudadanía: la necesaria vinculación entre los términos", en Un paisaje latinoamericano: historia, cultura y democracia, Universidad de Guadalajara y Centro Universitario de Ciencias Sociales y Humanidades, Guadalajara, Jalisco, pp.49-100.
Comins Mingol, Irene 1999, "Cultura para la paz. Hacia una búsqueda del reconocimiento", Ponencia presentada en Quartes Jornades de Foment de la Investigació. Universitat Jaume I, 11 de mayo, Castelló de la Plana, España.

Cardoso de Oliveira, Roberto, 1990, "La politización de la identidad y el movimiento indígena”, en José Alcina Franch (compilador), Indianismo e indigenismo en América Latina, Alianza Universidad, Madrid, pp. 145-161.

Cortina, Adela, 1998, Ciudadanos del mundo. Hacia una teoría de la ciudadanía, Alianza Editorial S.A., Madrid.

Crouch, Colin, 1999, "La ampliación de la ciudadanía social y económica y la participación”, en Soledad García y Steven Luckes (comps.) Ciudadanía: justicia social, identidad y participación, Siglo XXI Editores, España, pp. 257-285.

Dávalos, Pablo, 2006 'Ganamos pero perdimos': balance de lo logrado y problemas pendientes, en Raquel Gutiérrez y Fabiola Escárzaga (coordinadoras) Movimiento indígena en América Latina: resistencia y proyecto alternativo, Volumen II, Casa Juan Pablos, Centro de Estudios Andinos y Mesoamericanos y Benemérita Universidad Autónoma de Puebla, México, pp. 231-236.

Dávalos, Pablo (comp.), 2005a, Pueblos indígenas, estado y democracia. CLACSO, Quito.

Dávalos, Pablo, 2005b, "Movimientos indígenas en América Latina: el derecho a la palabra", en Pablo Dávalos (comp.) Pueblos indígenas, estado y democracia. CLACSO, Quito, pp. 17-33.

De la Peña, Guillermo 2006,a "Derechos Indígenas y ciudadanía étnica", texto preparado para el Seminario Nacional: Agenda del Desarrollo, 2006-2020, organizado por el Instituto de Investigaciones Económicas de la UNAM, marzo-mayo.

De la Peña, Guillermo 2006b, "Derechos indígenas, ciudadanía étnica y cambios constitucionales en México", en Christian Gros y Marie-Claude Strigler (coords.), Être indien dans les Amériques, Éditions de l'Institute des Amériques, IHEAL y Sorbonne Nouvelle, París, pp. 281-294.

De la Peña, Guillermo,1999a, "Notas preliminares sobre ciudadanía étnica (el caso de México)”, en Alberto J. Olvera (editor) La sociedad civil. De la teoría a la realidad. El Colegio de México, México, pp. 283-304. 
De la Peña, Guillermo, 1999b, “Territorio y ciudadanía étnica en la nación globalizada”, en Desacatos. Vol.1, Año 1, Primavera, pp. 13-27. Una versión preliminar se presentó en mayo de 1998 en el Homenaje a Claude Bataillon organizado por el IHEAL, el CREDAL y el CNRS en París.

De la Peña, Guillermo, 1995 "La ciudadanía étnica y la construcción de los 'indios' en el México contemporáneo.” Manuscrito presentado en versiones anteriores en la New School for Social Research de Nueva York y la Universidad de Texas en Austin. En ese mismo año fue publicada en la Revista Internacional de Filosofía Politica, No.6, Madrid, pp. 116-140.

Díaz Polanco, Héctor, 2004, El canon Snorri. Diversidad cultural y tolerancia, Universidad Autónoma de la Ciudad de México, México.

Díaz Polanco, Héctor, 1987, Etnia, nación y política, Juan Pablos Editor, México.

Díaz Polanco, Héctor, 1985, La cuestión étnico-nacional, Editorial Línea, México.

Eduardo Encalada, Fernando García y Kristine Ivarsdotter (consultores), 1999, "La participación de los pueblos indígenas y negros en el desarrollo del Ecuador", Reporte para el Banco Interamericano de Desarrollo, Washington, D.C. Tomado de: http:// www.mdb-egp.net/sds/doc/ind-KIvarsdotterS.pdf Escobar, Arturo, Sonia Álvarez y Evelina Dagnino (ed.) 2001, Política cultural. Cultura política, Taurus e ICANH, Colombia.

Flores, William y Rina Benmayor (editores), 1997, Latino Cultural Citizenship. Claiming Identity, Space and Rights, Beacon Press, Boston.

García Rojas, Gustavo. 2003. "Migración y desmemoria. La ciudadanía étnica en Monterrey”, en Trayectoria. Revista de Ciencias Sociales de la Universidad de Nuevo león, Año 5, No. 12, mayo-agosto del 2003.

Gledhill, John, 2002, "Los pasos difíciles a la ciudadanía amplia: mas allá de la transitología”, en Marco A. Calderón, Willem Assies y Ton Salman (editores) Ciudadania Cultural, politica y reforma del estado en América Latina, El Colegio de Michoacán y el Instituto Federal Electoral de Michoacán, Zamora, Michoacán, pp. 501-524.

González-Ponciano, Jorge Ramón, 1992, “Guatemala, el Estado y los Indígenas”, en Memorias del Primer Congreso
Internacional de Mayistas, UNAM, México, Tomo I, pp. 468-480.

Guerrero, Andrés, 2000, "El proceso de identificación: sentido común ciudadano, ventriloquia y transescritura”, en Andrés Guerrero (Comp.) Etnicidades, FLACSO Sede Ecuador, Quito, pp. 9-60.

Guerrero, Andrés, 1993, "De sujetos indios a ciudadanosétnicos: de la manifestación de 1961 al levantamiento indígena de 1990," en A. Alberto Adrianzén et al. Democracia, etnicidad y violencia politica en los países andinos, Instituto Francés de Estudios Latinos e Instituto de Estudios Peruanos, Lima, pp. 83-102.

Guerrero, Andrés, 1990, La desintegración de la identidad étnica en el Ecuador: de sujetos indios a ciudadanos étnicos. Documento de trabajo, Centro de Investigación de los Movimientos Sociales del Ecuador, Quito.

Gutiérrez, Raquel y Fabiola Escárzaga (coordinadoras), 2006, Movimiento indígena en América L atina: resistencia y proyecto alternativo, Volumen II, Casa Juan Pablos, Centro de Estudios Andinos y Mesoamericanos y Benemérita Universidad Autónoma de Puebla, México.

Gros, Christian, 2000, "Proyecto étnico y ciudadanía en América Latina”, en Políticas de la etnicidad. Identidad, Estado y modernidad. Instituto Colombiano de Antropología e Historia, Bogotá, pp. 118-126.

Harvey, Neil, 1998, "La autonomía indígena y ciudadanía étnica en Chiapas", en Boletín de Antropología Americana, No.32, julio, pp. 97-110. Se puede consultar en http://prisma.chadwyck.com/fullrec/fulltext. do?id=859300371 Honneth, Axel, 1997, La Lucha por el Reconocimiento. Por una gramática moral de los conflictos sociales, Crítica-Grijalbo Mondadori, Barcelona.

INEGI, 2000, XII Censo General de Población y Vivienda 2000, Instituto Nacional de Estadística, Geografía e Informática, México.

Jelin, Elizabeth, 1996, "La construcción de la ciudadanía: entre la solidaridad y la responsabilidad", en Elizabeth Jelin y Eric Hershberg (coordinadores) Construir la democracia. Derechos humanos, ciudadania y sociedad en América Latina. Editorial Nueva Sociedad, Venezuela, pp. 113-130.

Jelin, Elizabeth, 1994, “¿Ciudadanía emergente o exclusión? Movimientos sociales y ONGs en los años noventa", en Revista Mexicana de Sociología, Vol. 56, No.4, octubre-diciembre, pp. 91-108. 
Jelin, Elizabeth, 1993, “Cómo construir ciudadanía? Una visión desde abajo”, en Revista Europea de estudios latinoamericanos y del Caribe. Número 55, diciembre, pp. 21-38.

Jelin, Elizabeth (comp.), 1987, Ciudadania e identidad. Las mujeres en los movimientos sociales latino-americanos, Instituto de Investigaciones de las Naciones Unidas para el Desarrollo, Programa de Participación, Francia.

Jelin, Elizabeth y Eric Hershberg (coordinadores) 1996, Construir la democracia. Derechos humanos, ciudadania y sociedad en América Latina. Editorial Nueva Sociedad, Venezuela.

Kymlicka, Will, 1996, Ciudadanía multicultural, Paidós, Barcelona, Buenos Aires, México.

Laponce, Jean, 1995, "Ethnicity and citizenship as generators of each other", en Jean Laponce y William Safran (editores) Nationalism and Ethnic Politics, Vol. 1, No.3, pp. 1-8.

Leyva Solano, Xochitl, 2005, "Indigenismo, indianismo y 'ciudadania étnica' de cara a las redes neozapatistas", en Pablo Dávalos (compilador) Pueblos indígenas, estado y democracia. CLACSO, Quito, pp. 279-310, una versión preliminar de este texto se publicó en catalán en 2002. La ficha es: "Les lluites per la 'cuidadania etnica' a Chiapas”, en Revista d'Etnologia de Catalunya, No. 21, Novembre, Departament de Cultura. Generalitat de Catalunya, Barcelona, pp. 54-71.

Leyva Solano, Xochitl, 2001, “¡Chiapas es México! Autonomías indígenas: luchas políticas con una gramática moral”, en ICONOS. Revista de FLACSO Sede Ecuador, No.11, julio, Quito, pp. 110-125.

Leyva, Xochitl, Araceli Burguete y Shannon Speed (editoras), en prensa, Gobernar en la diversidad: experiencias indigenas desde América Latina. Hacia una investigación descolonizada activista, CIESAS, México.

Leyva, Xochitl, Mercedes Olivera y Araceli Burguete, 1999, "Los Pasos atrás en la Ley Albores", en el Diario La Jornada. Sección Derechos Indígenas del MASIOS ARE, domingo 28 de marzo de 1999, pp. 8-9.

Luckes, Steven y Soledad García, 1999, "Introducción”, en Soledad García y Steven Luckes (comps.), Ciudadania: justicia social, identidad y participación, Siglo XXI Editores, España, pp. 1-12.

Macas, Luis, 2005, "Entrevista a Luis Macas” realizada por Silvia Torralba el día 18 de noviembre. Tomada de http://ecuador.indymedia.org/
Macas, Luis, 2001, "Diez años del levantamiento del Inti Raymi: balance provisional”, en Yuyarinakuy, Ecuador.

Marshall, T.H. (1964) [1949] "Citizenship and Social Class”, en Class, Citizenship, and Social Development. Doubleday \& Company, New York.

Mallon, Florencia, 2003, Campesino y Nación. La construcción de México y Perú poscoloniales, Centro de Investigaciones y Estudios Superiores en Antropología Social, El Colegio de San Luis y El Colegio de Michoacán A.C., México.

Montoya, Rodrigo, 1998a, "Movimientos indígenas en América del Sur: potencialidades y límites”, publicado el 23 de agosto en: http://www.andes. missouri.edu/andes/Indice_Completo.html

Montoya, Rodrigo, 1998b, Multiculturalidad y política. Derechos indígenas, ciudadanos y humanos, Lima, SUR, Casa de Estudios del Socialismo.

Montoya, Rodrigo, 1992, Al borde del naufragio. Democracia, violencia y problema étnico en el Perú, SUR Casas de Estudios del Socialismo, Cuadernos del Sur, Lima.

Morales, Mario Roberto, 2000, "Problemática de la identidad ladina: una propuesta política”, en Revista Estudios Interétnicos, Año 8, Núm. 13, julio, Instituto de Estudios Interétnicos, Universidad de San Carlos, Guatemala, pp. 4-14.

Narotzky, Susana, 2005, Antropologías mundiales. $¿$ Podemos pensar fuera de los discursos hegemónicos? Mesa redonda realizada en el 1er Congreso de la Asociación Latinoamericana de Antropología, 11-15 de julio en Rosario, Argentina. Tomado de http://ram-wan.net.

Navarro, Alejandra, 2006, Los indígenas no hablan “bien”. Defensores comunitarios, ciudadanía étnica y retos ante el racismo estructural en México, ponencia presentada en el $V$ Congreso de la Red Latinoamericana de Antropología Juridica. Justicia y diversidad en tiempos de globalización, celebrado del 10 al 20 de octubre en Oaxtepec, Morelos.

Quijano, Anibal, 1999, "Colonialidad del poder, cultura y conocimiento en América Latina”, en Santiago Castro Gómez, Oscar Guardiola-Rivera, Carmen Millán de Benavides (editores) Pensar (en) los intersticios. Teoría y práctica de la crítica poscolonial, Santa Fe de Bogotá, Pontificia Universidad Javeriana e Instituto de Estudios Sociales y Culturales- Pensar, pp. 99-109.

Pacari, Nina, 2006, "El auge de las identidades como respuesta política”, en Milka Castro (editora) Desafios 
Xochitl Leyva Solano

de la interculturalidad: Identidad, politica y derecho, Universidad de Chile, Santiago de Chile, pp. 35-54.

Peyser, Alexia y Juan Chackiel s/f, "La identificación de poblaciones indígenas en los censos de América Latina."

Tomado de www.cepal.org/publicaciones/xml/6/4436/ lc11204e.pdf, Plascencia de la Parra, Enrique, 1996, La invención del Quinto Centenario. Antología, INAH, México.

Procacci, Giovanna, 1999, "Ciudadanos pobres. La ciudadanía social y la crisis de los estados de bienestar”, en Soledad García y Steven Luckes (comps.), Ciudadania: justicia social, identidady participación, Siglo XXI Editores, España, pp. 15-44.

Rojas Cortés, Angélica, 2000, "La búsqueda de la ciudadanía étnica 'desde abajo'”, en Miguel Bazdresch (coord.), Memoria del congreso gobiernos locales: el futuro politico de México, Guadalajara, Instituto Tecnológico de Estudios Superiores de Occidente, IGLOM, pp. 297-302.

Rosaldo, Renato 1997 "Cultural Citizenship, Inequality, and Multiculturalism”, en William Flores y Rina Benmayor (editores) Latino Cultural Citizenship. Claiming Identity, Space and Rights, Beacon Press, Boston, pp. 27-38.

Rosaldo, Renato, 1994, "Cultural Citizenship and Educational Democracy”, en Cultural Anthropology, Vol. 9, Número 3, Agosto, pp. 402-411.

Rosaldo, Renato, 1989, Culture and Truth. The Remaking of Social Análisis, Beacon Press, Boston.

Rosaldo, Renato, 1985, "Assimilation Revisited" Stanford Centre for Chicago Research, Working Paper Series Número 9, Julio, Stanford California.

Sarmiento Silva, Sergio, 1998, Voces indias y V Centenario, INAH, México.

Somers, Margaret R., 1999, "La ciudadanía y el lugar de la esfera pública: un enfoque histórico”, en Soledad García y Steven Luckes (comps.), Ciudadanía: justicia social, identidad y participación, Siglo XXI Editores, España, pp. 217-233.
Stanvenhagen, Rodolfo, 2000, Conflictos étnicos y Estadonación, Siglo XXI, México.

Stinchcombe, A.L., 1975, "Social Structure and Politics: Macropolitical Theory”, en F. Greenstein y N. Polsby, Macropolitical Theory, Addison Wesley, Massachussets, pp. 557-622.

Tibán, Lourdes y Fernando García, en prensa, "Entre la oposición y el enfrentamiento al diálogo y las alianzas: la experiencia de la CONAIE y el MICC en Ecuador”, en Xochitl Leyva, Araceli Burguete y Shannon Speed (editoras), Gobernar en la diversidad: experiencias indigenas desde América Latina. Hacia una investigación descolonizada activista, CIESAS, México.

Ticona Alejo, Esteban, 2005, "La rebelión aymara y popular de octubre de 2003. Una aproximación desde algunos barrios paceños de la Paz, Bolivia”, en Pablo Dávalos (comp.), Pueblos indígenas, estado y democracia, CLACSO, Quito, pp. 185-196.

Toledo, Víctor, 2005, "Políticas indígenas y derechos territoriales en América Latina 1990-2004, ¿Las fronteras indígenas de la globalización?", en Pablo Dávalos (comp.), Pueblos indígenas, estado y democracia, CLACSO, Quito, pp. 67-102.

Villoro, Luis, 2002, “Ciudadanía y Estado Plural”, en Diego Iturralde, Luis Villoro, Will Kymlicka y Rolando Castillo, Democracia, ciudadanía y diversidad: el debate político, Programa de Naciones Unidas Sede Guatemala, Quetzaltenango, Guatemala.

Zárate, Eduardo J., 2002, "Ciudadanía, comunidad y modernidades étnicas”, en Marco A. Calderón, Willem Assies, Ton Salman (editores) Ciudadanía, Cultura, política y Reforma del Estado en América latina. El Colegio de Michoacán, A.C., Zamora, Michoacán, pp. 407-427, Una primera versión fue presentada en 2001 como ponencia en el XXIII Coloquio de Antropología e Historia Regionales. Ciudadania, Cultura Politica y Reforma del Estado en América Latina, Zamora, Michoacán, El Colegio de Michoacán A.C. 